\title{
Communication \\ Identification of New Dioxygenases Able to Recognize Polycyclic Aromatic Hydrocarbons with High Aromaticity
}

\author{
Apolonia Rodríguez ${ }^{1}$, Sandra G. Zárate ${ }^{2}$ and Agatha Bastida ${ }^{3, *(1)}$ \\ 1 Carrera de Ingeniería Ambiental, Universidad Mayor Real y Pontificia San Francisco Xavier de Chuquisaca, \\ Sucre P.O. Box 212, Bolivia; rodriguez.apolonia@usfx.bo \\ 2 Carrera de Ingenieria en Gestion Ambiental, Universidad Privada Domingo Savio, Sucre P.O. Box 212, Bolivia; \\ su.sandra.zarate.v@upds.net.bo \\ 3 Departamento de Química Bio-Orgánica, Instituto de Química Orgánica General, Consejo Superior de \\ Investigaciones Científicas (CSIC), c/Juan de la Cierva 3, E-28006 Madrid, Spain \\ * Correspondence: agatha.bastida@csic.es; Tel.: +34-913809614
}

check for updates

Citation: Rodríguez, A.; Zárate, S.G.; Bastida, A. Identification of New Dioxygenases Able to Recognize Polycyclic Aromatic Hydrocarbons with High Aromaticity. Catalysts 2022, 12, 279. https://doi.org/10.3390/ catal12030279

Academic Editors: Keith Hohn

Kotohiro Nomura, Evangelos

Topakas, Vincenzo Baglio, C.

Heath Turner, Leonarda

Francesca Liotta, Jean-François

Lamonier and Maria A. Goula

Received: 14 February 2022

Accepted: 1 March 2022

Published: 2 March 2022

Publisher's Note: MDPI stays neutral with regard to jurisdictional claims in published maps and institutional affiliations.

Copyright: (C) 2022 by the authors. Licensee MDPI, Basel, Switzerland. This article is an open access article distributed under the terms and conditions of the Creative Commons Attribution (CC BY) license (https:// creativecommons.org/licenses/by/ $4.0 /)$

\begin{abstract}
Polycyclic aromatic hydrocarbons (PAHs), products from the incomplete combustion of crude oil, are pollutants present in nature. Ring hydroxylating dioxygenase enzymes are able to catalyze polycyclic aromatic hydrocarbons in the biodegradation process with a high degree of stereo-, regio-, and enantiospecificity. In this work, we present the first approximation of the binding modes of 9 PAHs with high aromaticity in the catalytic sites of biphenyl or naphthalene dioxygenases from four microorganisms usually used in bio-remediation processes: Sphingobium yanoikuyae, Rhodococcus jostii RHA1, Pseudomonas sp. C18, and Paraburkholderia xenovorans. Molecular modeling studies of two biphenyl dioxygenases from Sphingobium yanoikuyae and Paraburkholderia xenovorans showed good binding affinity for PAHs with 2-4 benzene rings (fluoranthene, pyrene, and chrysene), and both enzymes had a similar amount of substrate binding. Molecular docking studies using naphthalene dioxygenase from Pseudomonas sp. C18 showed that the enzyme is able to accommodate PAHs with high aromaticity (benzo(a)pyrene, indeno(1,2,3-cd)pyrene), with good docking scores. This study provides important insight into the utility of naphthalene dioxygenases in the degradation of HAPs with high aromaticity.
\end{abstract}

Keywords: biodegradation; dioxygenase; molecular modeling; polycyclic aromatic hydrocarbons

\section{Introduction}

Polycyclic aromatic hydrocarbons (PAHs), products from the incomplete combustion of crude oil, are pollutants present in nature [1,2]. There are more than 100 PAHs; their hydrophobicity increases and solubility decreases with an increased number of benzene rings. These compounds are of environmental concern because of their toxic, mutagenic, and carcinogenic properties [3]. Bioremediation is a highly efficient and cost-effective process that mainly uses microorganisms or enzymes (dioxygenases) to degrade contaminants in the environment (Figures S1 and S2) [4-6]. Communities of microorganisms with the capacity to degrade low-molecular-weight polycyclic aromatic hydrocarbons have been isolated and characterized, but those microorganisms were much less able to degrade high-molecularweight PAHs ( $>4$ benzene rings) [7-12]. Naphthalene is biodegraded by Sphingomonas (96\%) [13], Sphingobiun, Actinobacteria, and Rhodococcus (100\%). Anthracene is decomposed by Actinobacteria (93\%), Sphingobium (28\%), Mycobacterium (50-70\%), Rhodococcus (90\%), Nocardia, and Paracoccus [14]. Pyrene, fluoranthene, and chrysene are decomposed by Sphingomonas (80-90\%), Rhodococcus (90\%), Dyadobacter, Mycobacterium (50-70\%), Sphingobium (20-60\%), Pseudomonas aeroginos (60-70\%), and Dyadobacter koreensis (80\%) (Table S1) [8]. The concentration of PAHs with 2-3 benzene rings in nature decreases faster than the concentration of PAHs with 4-6 rings, which may be due to a recalcitrant effect or a lack of microorganisms capable of degrading these compounds [15]. 
PAH degradation by bacteria proceeds through dioxygenase attacks on a PAH to form a cis-dihydrodiol aromatic compound using two atoms of $\mathrm{O}_{2}$ (Figure 1) [16,17] These proteins are also able to perform oxidation with a high degree of stereo-, regio-, and enantiospecificity at the catalytic mononuclear iron site [18]. Dioxygenases are metalloenzymes present in a wide variety of microorganisms that are able to oxidize PAHs using oxygen molecules and two electrons from a reductase to give cis-arene diols (Figure 1) $[19,20]$. A wide range of 3D dioxygenase structures have been determined, giving insight into substrate recognition and regioselectivity $[19,21]$. The structure of most dioxygenases is an $\alpha_{3} \beta_{3}$ hexamer molecule, with each alpha subunit containing a Rieske [2Fe-2S] cluster and another alpha subunit containing a mononuclear iron center, where the catalytic reaction takes place [22,23]. The catalytic domain of these enzymes is antiparallel sheets, and the active site contains an $\mathrm{Fe}^{3+}$ ion usually coordinated by 2 His and 1 Asp amino acid [16]. In the Rieske center, Fe- 1 is coordinated by 2 Cys and the second Fe by 2 His being conserved in this family of enzymes (Figure 1) [22].

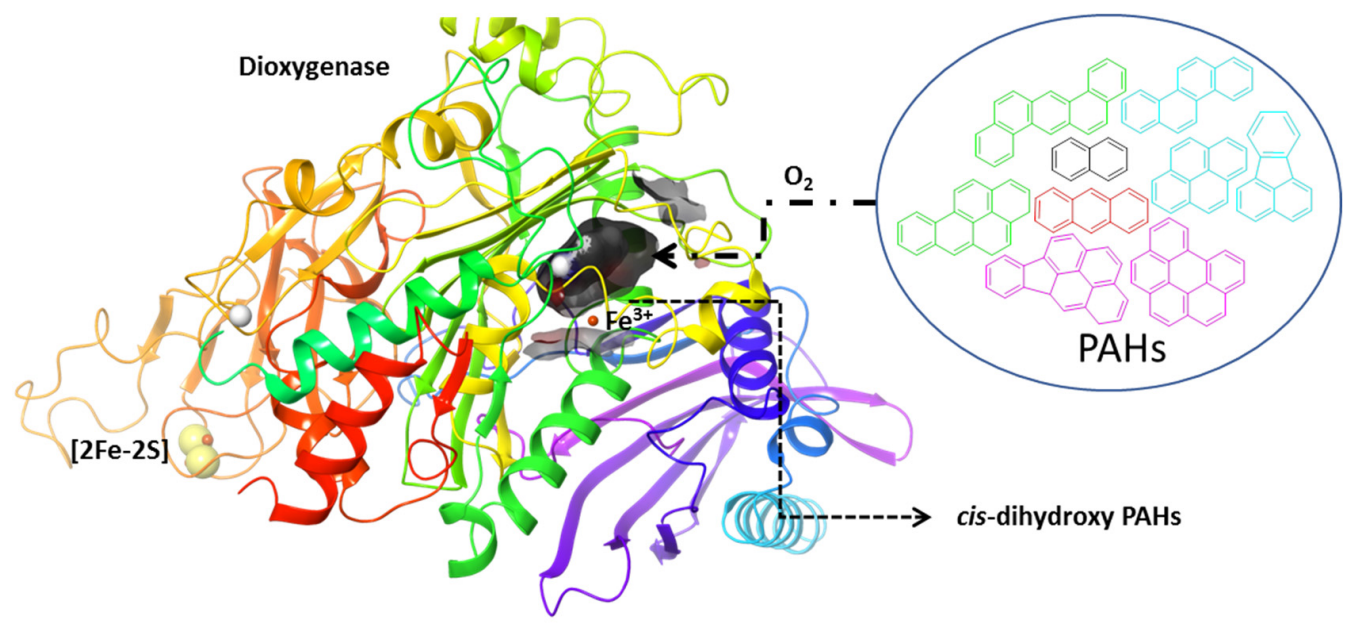

Figure 1. Schematic presentation of dioxygenase from Rhodococcus jostii RHA1 (Protein Data Bank ID 1ulj). PAHs and oxygen molecule are substrates in binding sites of dioxygenase $\left(\mathrm{Fe}^{3+}\right)$ to produce cis-hydroxylated compounds.

Dioxygenases from different organisms have been studied for the deoxygenation of low PAHs (1-3 benzene rings). In particular, dioxygenase from Sphingomonas CHY-1 has been described as capable of recognizing different PAHs using molecular modeling [13,16,24]. Computational tools can be very useful for finding dioxygenases capable of degrading highly condensed PAHs, allowing these enzymes to be used in biocatalytic processes. In this paper, we carried out molecular docking studies of dioxygenases from different microorganisms involved in the biodegradation of highly condensed PAHs that are present in nature.

\section{Results and Discussion}

Genes responsible for the degradation of PAHs were studied for the first time in strains of Pseudomonas putida isolated in culture media with naphthalene or phenanthrene as the only carbon source (Figure S2b). Bacteria generally present high metabolic versatility and are capable of utilizing a broad spectrum of PAHs. To carry out the molecular docking studies, we selected naphthalene and biphenyl dioxygenases with 3D structure solved (PDB ID 2gbx, 1ulj, 4hjl, and 2xsh) from Sphingomonas, Rhodococcus, Pseudomonas, and Paraburkholderia (Table 1). 
Table 1. Protein Data Bank ID codes of dioxygenases from different microorganisms.

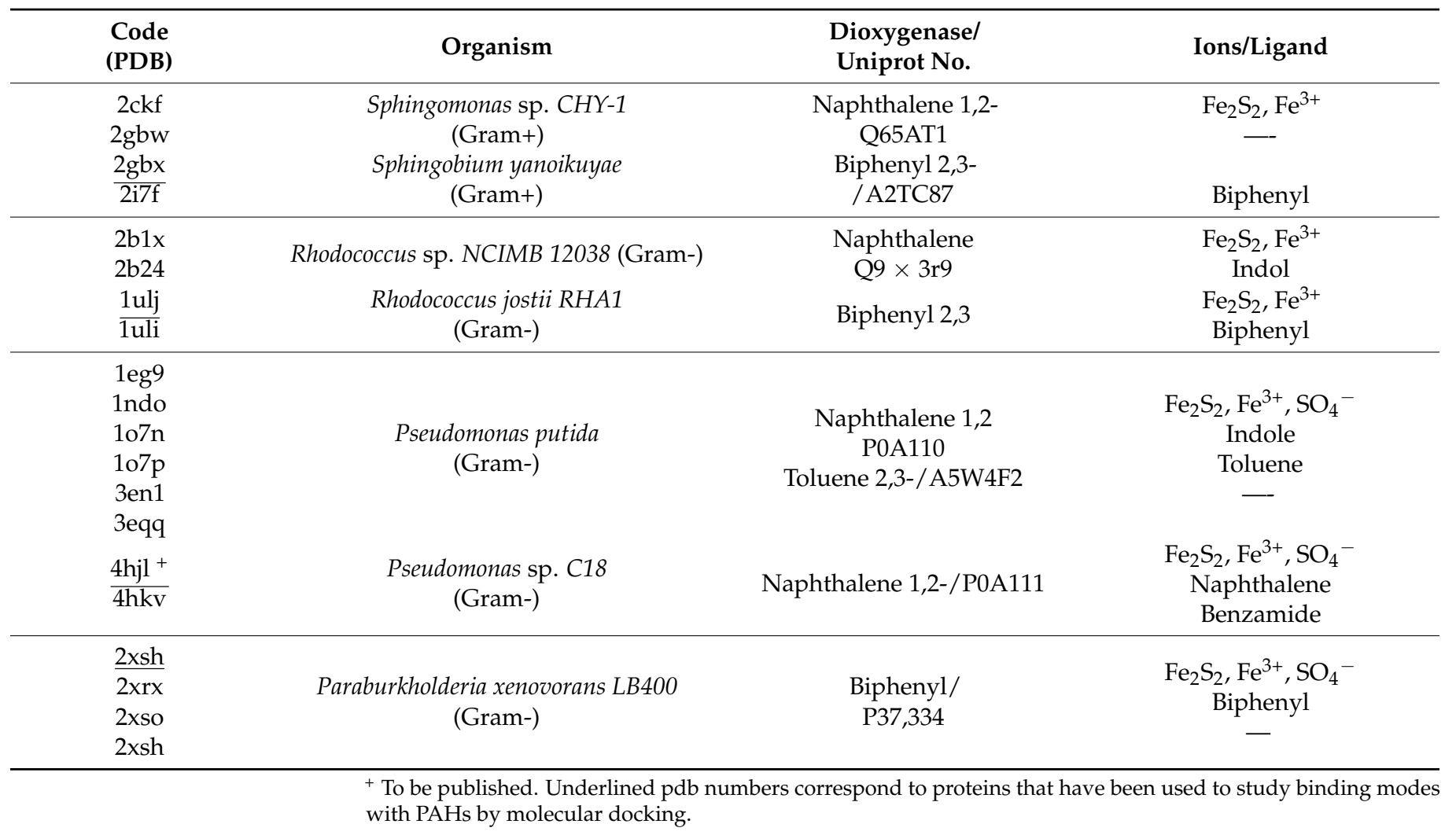

The PAHs used in this study were anthracene, naphthalene, pyrene, chrysene, fluoranthene, benzo(a)pyrene, dibenzo(a,h)anthracene, indeno(1,2,3-cd)pyrene, and benzo(ghi) perylene (Figure 2). We chose these PAHs because they are listed by the United States Environmental Protection Agency (EPA) as priority pollutants.

The oxidation of these aromatic compounds by dioxygenases from different microorganisms is described in Table S1. Most dioxygenases are able to recognize up to three benzene rings (biphenyl, naphthalene, and anthracene); few enzymes are able to degrade compounds with more benzene rings [25].

Sphingobium yanoikuyae strain B1 was able to oxidize low-molecular-weight PAHs with four benzene rings (chrysene, pyrene, and fluorenthene) in in vitro assays [25]. Molecular modeling studies of PAHs into biphenyl 2,3-dioxygenase from Sphingobium yanoikuyae (PDB ID 2gbx) have shown that naphthalene, anthracene, fluoranthene, pyrene, and chrysene interact with nearby hydrophobic amino acid (F350, F201, L305, F404, V208, and T308) (Figure 3a). The experimental data support this enzyme as a good degrader of 2-4 benzene rings. PAHs were bound in the same hydrophobic internal pocket that the biphenyl substrate presents in the 3D structure of the protein. The chrysen-dioxygenase complex presents three Pi-Pi stacking interactions with two His (H207 and H293) of the enzyme in the binding site, giving a good docking score $(-7.6 \mathrm{kcal} / \mathrm{mol})$ (Table S3, Figure $3 \mathrm{~b})$. The surface area of the catalytic pocket of this enzyme is $361.44 \AA^{2}$, so it is not surprising that it would not be able to accommodate larger PAHs (Table S2). 

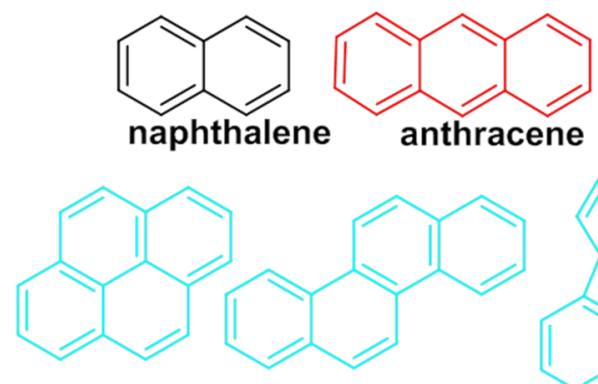

pyrene

chrysene<smiles></smiles>

fluoranthene<smiles>C1=C2Cc3cc4ccccc4c4ccc(c2c34)C1</smiles><smiles>c1ccc2c(c1)ccc1cc3ccc4ccccc4c3cc12</smiles>

benzo(a)pyrene

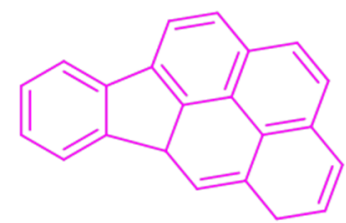

\section{indeno(1,2,3-cd)pyrene}

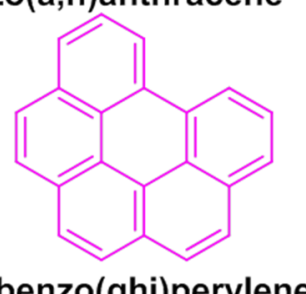

Figure 2. Structure of polycyclic aromatic hydrocarbons (PAHs) present in the environment as pollutants. Solubility (mg/mL): naphthalene, 31.7; anthracene, 0.07 ; pyrene, 0.14 ; chrysene, 0.0006 ; fluoranthene, 0.26; benzo(a)pyrene, 0.003; dibenzo(a,h)anthracene, 0.0005; indeno(1,2,3-cd)pyrene, 0.062 ; and benzo(ghi)perylene, 0.062 .

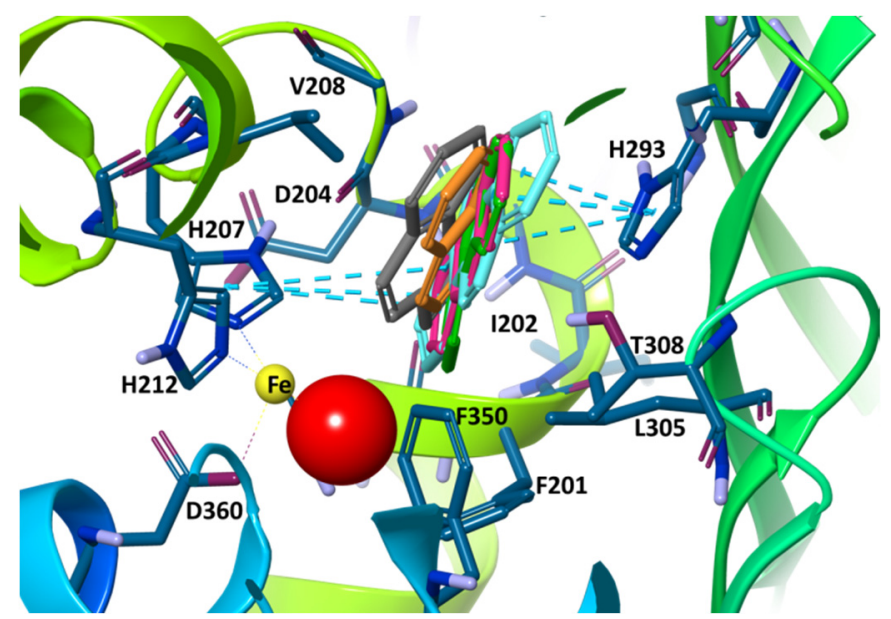

(a)

Figure 3. Cont. 


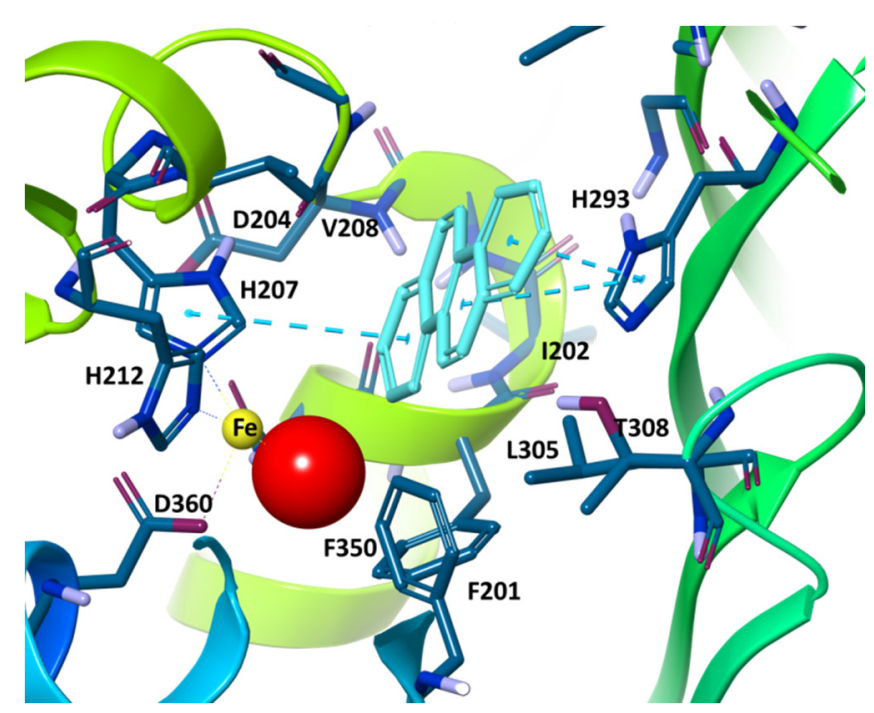

(b)

Figure 3. (a) Model of naphthalene (orange), anthracene (pink), fluoranthene (green), pyrene (gray), and chrysene (cyan) docked into binding site of biphenyl dioxygenase from Sphingobium yanoikuyae (ID 2gbx), with docking scores of $-5.1,-7.6,-6.9,-7.1$, and $-7.6 \mathrm{kcal} / \mathrm{mol}$, respectively (Table S3). Red ball is an oxygen molecule, and dashed cyan lines indicate aromatic staking interaction in the catalytic pocket. (b) Model of chrysene docked into substrate pocket.

The same study was carried out with another biphenyl dioxygenase from Paraburkholderia xenovorans (also known as Burholderia xenovorans PDB ID 2xsh), which has a similar molecular surface area in the binding pocket of biphenyl dioxygenase from Sphingobium yanoikuyae (421.550 $\AA^{2}$ ) (see Supporting Materials). In addition, the amino acids that form the catalytic pocket are very similar in both enzymes (phenylalanines and histidines). The enzyme co-metabolizes many polychlorinated biphenyl compounds and has become a model system for the bacterial breakdown of very persistent environmental contaminants [26]. Figure 4 shows the binding of naphthalene, anthracene, fluoranthene, pyrene, and chrysene in the catalytic pocket, where their positions and conformations lie in very similar positions. The docking score results and structural features were very similar between these two biphenyl 2,3-enzymes. These studies demonstrate that the PAH binds in the enzyme with the atoms that would be oxidized closest to the Fe ion. Then, the enzymes can control the substrate orientation, as in product stereoselectivity/regioselectivity.

Rhodococcus wratislaviensis IFP 2016 and Rhodococcus aetherivorans IFP 2017 were able to degrade 15 petroleum compounds (low-molecular-weight PAHs or aliphatic compounds: xylene, toluene, octane, and so on) (Table S2) [27]. The molecular docking of 9 PAHs into biphenyl dioxygenase from Rhodococcus jostii RHA1 (PDB ID 1ulj) revealed that only naphthalene and anthracene could be accommodated in the binding site, with good docking scores of -6.7 and $-7.3 \mathrm{kcal} / \mathrm{mol}$, respectively (Table S3) (Figure 5), although the enzyme presents a large catalytic pocket (surface area of $1360.404 \AA^{2}$ ). Naphthalene and anthracene share similar special occupancies with two aromatic staking interactions in the catalytic pocket (F368 residue for naphthalene and H224 for anthracene) (Figure 5). This result may be due to the ability of the enzyme's catalytic pocket to recognize low-molecular-weight PAHs. 


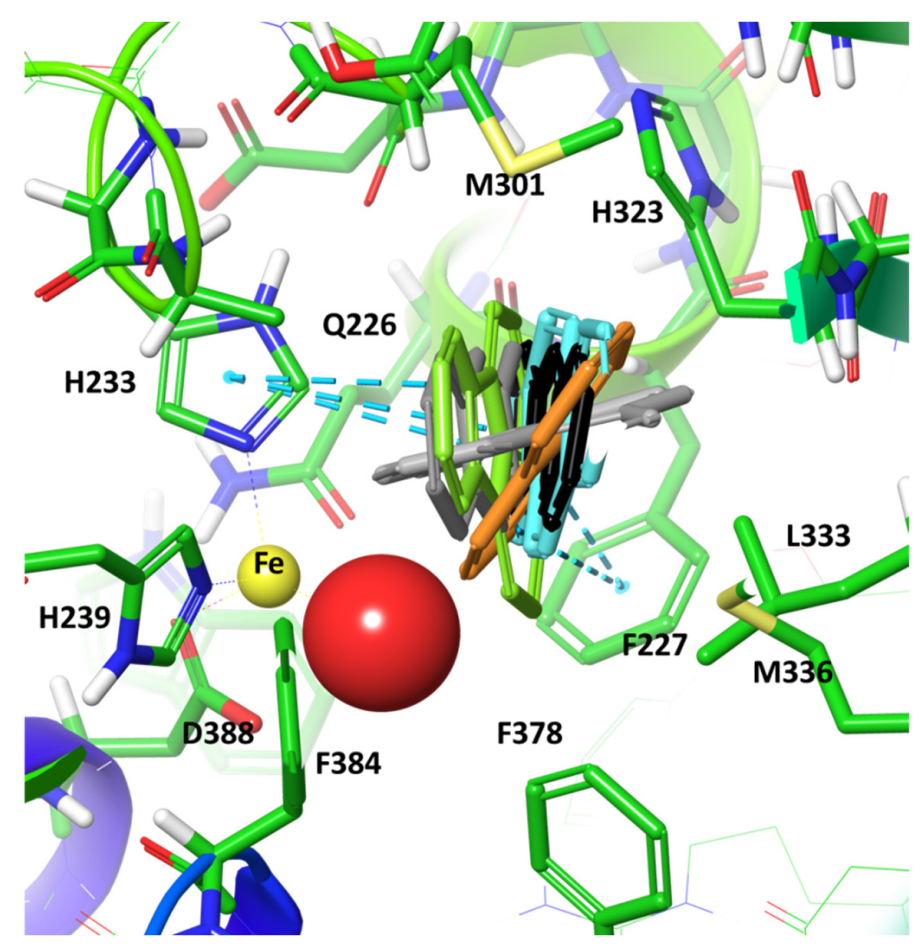

Figure 4. Molecular docking of naphthalene (orange), anthracene (black), fluoranthene (green), pyrene (gray), and chrysene (cyan) in catalytic pocket of dioxygenase from Paraburkholderia xenovorans LB400 (ID 2xsh), with docking scores of $-5.9,-8.3,-6.5,-7.9$, and -8.4 , respectively. Red ball represents oxygen molecule, and Fe ion interacts with His233, Asp388, and His239.

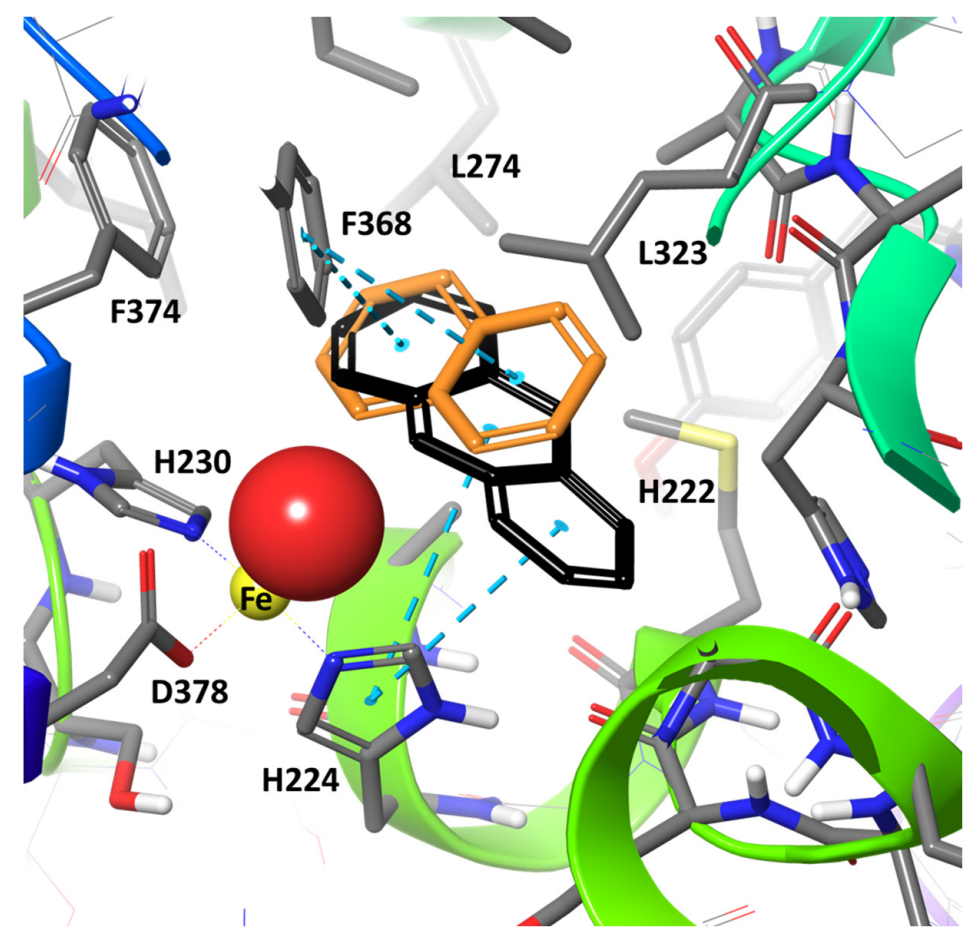

Figure 5. Three-dimensional conformation and contact of anthracene (orange) and naphthalene (black) in binding site of biphenyl dioxygenase from Rodococcus jostii RHA1 (ID 1ulj), with docking scores of -6.7 and $-7.3 \mathrm{kcal} / \mathrm{mol}$, respectively. Remaining binding site residues not shown to clarify the picture. 
The biodegradation of PAHs in a culture made up of a consortium of five microorganisms, including Pseudomonas aeruginosa, was able to completely eliminate benzo(k) fluoranthene, indeno(1,2,3-cd)pyrene, and dibenzo(a,h)anthracene [28]. Docking studies with PAHs inside the substrate pocket of naphthalene dioxygenase from Pseudomonas sp. C18 (ID 4hjl) (Figure 6 Table S3) reveal that seven PAHs interacted with hydrophobic amino acids (F202, A206, V260, V209, L207, F224, I408, and L253) (Figure 6) by Pi-Pi staking interactions. The docking scores with benzo(a)pyrene (five benzene rings) and indeno(1,2,3cd)pyrene (six rings) into the naphthalene enzyme ( -9.9 and $-9.0 \mathrm{kcal} / \mathrm{mol}$, respectively) were analyzed (Figure 6).

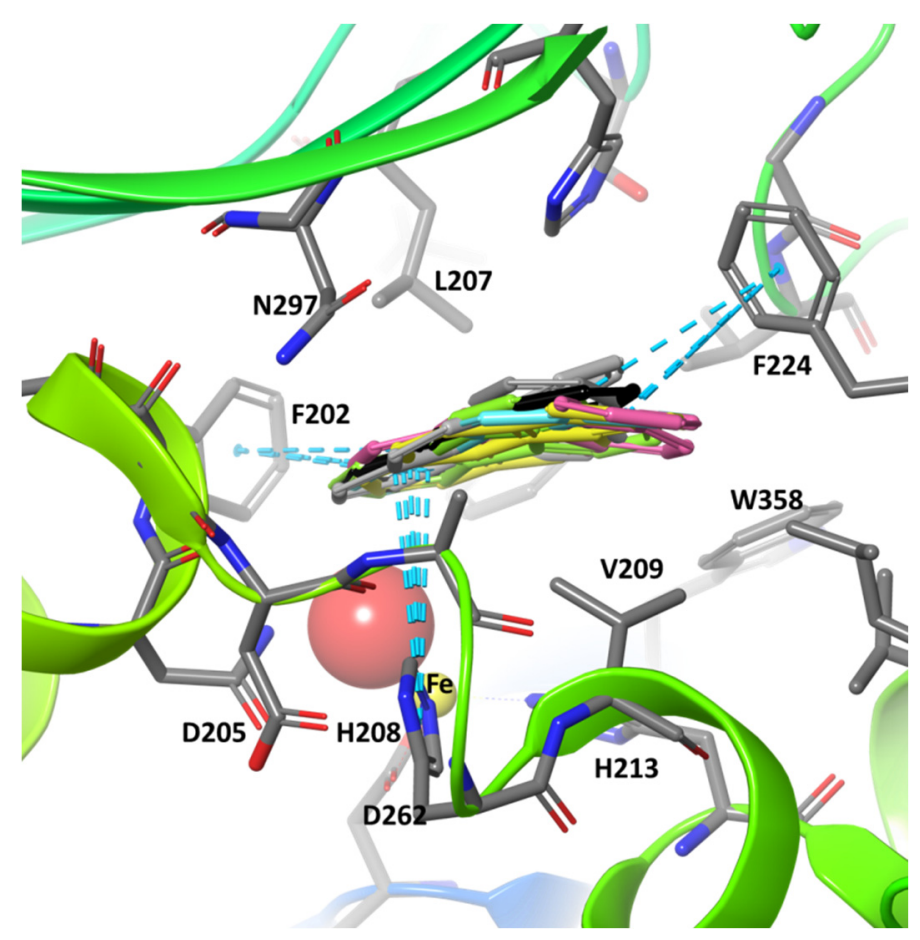

Figure 6. Model of naphthalene (orange), anthracene (pink), fluoranthene (green), pyrene (gray), chrysene (cyan), benzo(a)pyrene (yellow), and indeno(1,2,3-cd)pyrene (salmon) docked into binding site of naphthalene dioxygenase from Pseudomonas sp. C18 (ID 4hjl), with docking scores of $-6.1,-7.6$, $-8.1,-8.1,-8.9,-9.9$, and 9.0 (purpura) $\mathrm{kcal} / \mathrm{mol}$, respectively. Remaining binding site residues not shown to clarify the picture.

Residues F202, F224, and H208 are expected to affect the topology of the binding pocket and consequently select the shape of allowed PAHs (Figure 7). So, the protein could oxidize a wide range of PAHs because its binding site is large enough to accommodate up to six rings.

Dibenzo(a,h)anthracene and benzo(ghi)perylene (five or six fused aromatic rings) did not interact within any dioxygenases used in this study. Molecular modeling studies provide important insights into the utility of naphthalene or biphenyl dioxygenases in the degradation of HAPs with high aromaticity. 


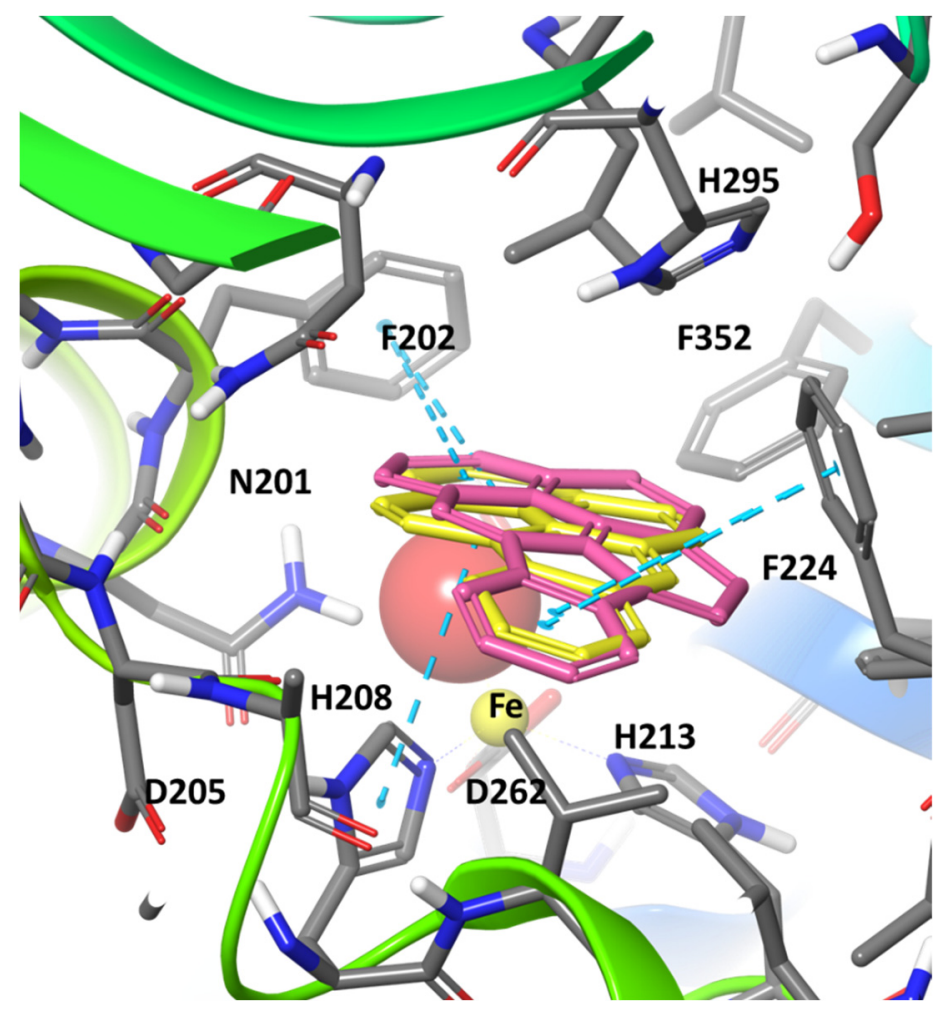

Figure 7. Molecular docking of benzo(a)pyrene (yellow) and indeno(1,2,3-cd)pyrene (salmon) into naphthalene dioxygenase from Pseudomonas sp. C18 (ID 4hjl), with docking scores of -9.9 and $-9.0 \mathrm{kcal} / \mathrm{mol}$, respectively. Dashed cyan lines indicate aromatic staking interaction in catalytic pocket (Phe224, Phe202, and H208). Red ball represents oxygen molecule. Fe interacts with His213, Asp362, and His208. Remaining binding site residues not shown to clarify the picture.

\section{Materials and Methods}

The docking evaluation was carried out for four proteins (Table 1). The crystal structure of the dioxygenases used in this evaluation was retrieved from the Protein Data Bank (PDB). The catalytic $\alpha$-subunit was selected, and all water molecules were removed. An oxygen molecule was placed near the Fe ion [29], and a 3D structure model of the proteins was optimized using the Protein Preparation Wizard tool integrated in Maestro (Schrödinger, New York, NY, USA) [30]. Missing hydrogen atoms were added, assuming the standard protonation state of titratable residues. The grid of the enzymes was using the receptor grid generation tools in Glide. The size of the docked molecules was set to within $20 \AA$. The molecular surface of the proteins and ligands was carried out using the binding surface area analysis tool integrated in Maestro.

Three-dimensional structures of the PAHs were retrieved from PubChem with extension. sdf and CID: anthracene 8418, naphthalene 931, fluoranthene 9154, pyrene 31423, chrysene 9171, benzo(a)pyrene 2336, dibenzo(a,h)anthracene 5889, indeno(1,2,3-cd)pyrene 9131, and benzo(ghi)perylene 115240. These compounds were prepared using the LigPrep module in the Schrödinger package. All polycyclic aromatic hydrocarbons were minimized using the OPLS3e force field implemented in Maestro. Molecular dynamic simulations of protein-PAH complexes were carried out using the Schrödinger bioinformatics suite. To achieve this, molecular docking was performed using the Glide-dock XP module [31,32]. Ligand poses generated in this way were run through a series of hierarchical filters to evaluate ligand interactions with the receptor. Docking score, glide e-model, ionization penalty, glide gscore, and TPSA were used to select the docking poses. 


\section{Conclusions}

Molecular modeling was performed in an attempt to identify novel dioxygenases from microorganisms able to degrade PAHs with high aromaticity. Biphenyl dioxygenase from Rodococcus jostii RHA1 only showed binding of naphthalene and anthracene (smallest PAHs). The other two biphenyl dioxygenases, from Sphingobium yanoikuyae and Paraburkholderia xenovorans, showed good binding affinity for 5 of the 9 PAHs studied (particularly fluoranthene, pyrene, and chrysene), and both enzymes had very similar volumes of substrate binding (421.550 and $361.44 \mathrm{~A}^{2}$, respectively). Molecular docking of 9 PAHs into naphthalene dioxygenase from Pseudomonas sp. C18 showed the good accommodation of seven PAHs (5-6 fused aromatic rings) that presented large, accessible surface areas (1500.585 $\AA^{2}$ ). This study shows that structural features are essential for determining the binding mode of PAHs. This study provides important insight into the utility of naphthalene dioxygenases in the degradation of PAHs with high aromaticity.

Supplementary Materials: The following supporting information can be downloaded at https:/ / www.mdpi.com/article/10.3390/catal12030279/s1: Figure S1. Main principles of aerobic degradation of PAHs; Figure S2. (a) Bioremediation of PAHs by microorganism and (b) pathways for degradation of naphthalene by Pseudomonas putida; Table S1. PAH biodegradation by different microorganisms; Table S2. Molecular surface area of dioxygenases and PAHs; Table S3. Docking scores of biodegraded PAHs by dioxygenases from different microorganisms.

Author Contributions: Conceptualization, A.B. and A.R.; methodology, S.G.Z.; software, S.G.Z.; formal analysis, A.R.; investigation, A.B. and A.R.; resources, S.G.Z. and A.R.; writing-original draft preparation, A.B.; writing-review and editing, A.R. and S.G.Z.; supervision, A.B. All authors have read and agreed to the published version of the manuscript.

Funding: This research received no external funding.

Conflicts of Interest: The authors declare no conflict of interest.

\section{References}

1. Sahoo, B.M.; Ravi Kumar, B.V.V.; Banik, B.K.; Borah, P. Polyaromatic Hydrocarbons (PAHs): Structures, Synthesis and their Biological Profile. Curr. Org. Synth. 2020, 17, 625-640. [CrossRef]

2. Patel, A.B.; Shaikh, S.; Jain, K.R.; Desai, C.; Madamwar, D. Polycyclic Aromatic Hydrocarbons: Sources, Toxicity, and Remediation Approaches. Front. Microbiol. 2020, 11, 1-23. [CrossRef] [PubMed]

3. Abdel-Shafy, H.I.; Mansour, M.S.M. A review on polycyclic aromatic hydrocarbons: Source, environmental impact, effect on human health and remediation. Egypt. J. Pet. 2016, 25, 107-123. [CrossRef]

4. Cerniglia, C.E. Biodegradation of polycyclic aromatic hydrocarbons. Biodegradation 1992, 3, 351-368. [CrossRef]

5. Juhasz, A.L.; Naidu, R. Bioremediation of high molecular weight polycyclic aromatic hydrocarbons: A review of the microbial degradation of benzo[a]pyrene. Int. Biodeterior. Biodegrad. 2000, 45, 57-88. [CrossRef]

6. Viñas, M.; Solanas, A. Biorremediación de Suelos Contaminados por Hidrocarburos: Caracterización Microbiológica, Química y Ecotoxicológica. Ph.D. Thesis, Universitat de Barcelona, Barcelona, Spain, 2005.

7. Desai, A.M.; Autenrieth, R.L.; Dimitriou-Christidis, P.; McDonald, T.J. Biodegradation kinetics of select polycyclic aromatic hydrocarbon (PAH) mixtures by Sphingomonas paucimobilis EPA505. Biodegradation 2008, 19, 223-233. [CrossRef]

8. Vaidya, S.; Devpura, N.; Jain, K.; Madamwar, D. Degradation of chrysene by enriched bacterial consortium. Front. Microbiol. 2018, 9,1-14. [CrossRef]

9. Rodríguez-gonzales, A.; Zárate-villarroel, S.G.; Bastida-codina, A. Biodiversidad Bacteriana Presente en Suelos Contaminados con Hidrocarburos Para Realizar Biorremediación; Universidad Nacional de Costa Rica: Heredia, Costa Rica, 2022; Volume 56, ISBN 0000000251419.

10. Roszak, M.; Jabłó Nska, J.; Stachurska, X.; Dubrowska, K.; Kajdanowicz, J.; Goł̣ Ebiewska, M.; Kiepas-Kokot, A.; Osí Nska, B.; Augustyniak, A.; Karakulska, J. Development of an Autochthonous Microbial Consortium for Enhanced Bioremediation of PAH-Contaminated Soil. Int. J. Mol. Sci. Artic. 2021, 22, 13469. [CrossRef]

11. Thomas, S.; Veettil, N.T.; Subbiah, K. Isolation, characterization and optimization of chrysene degradation using bacteria isolated from oil-contaminated water. Water Sci. Technol. 2021, 84, 2737-2748. [CrossRef]

12. Morillo, E.; Madrid, F.; Lara-Moreno, A.; Villaverde, J. Soil bioremediation by cyclodextrins. A review. Int. J. Pharm. 2020, 591, 1-16. [CrossRef]

13. Jouanneau, Y.; Meyer, C.; Duraffourg, N. Dihydroxylation of four- and five-ring aromatic hydrocarbons by the naphthalene dioxygenase from Sphingomonas CHY-1. Appl. Microbiol. Biotechnol. 2016, 100, 1253-1263. [CrossRef] [PubMed] 
14. Mutnuri, S.; Vasudevan, N.; Matthias, K. Degradation of anthracene and pyrene supplied by microcrystals and non-aqueous-phase liquids. Appl. Microbiol. Biotechnol. 2005, 67, 569-576. [CrossRef] [PubMed]

15. Kanaly, R.A.; Harayama, S. Biodegradation of high-molecular-weight polycyclic aromatic hydrocarbons by bacteria. J. Bacteriol. 2000, 182, 2059-2067. [CrossRef] [PubMed]

16. Jakoncic, J.; Jouanneau, Y.; Meyer, C.; Stojanoff, V. The catalytic pocket of the ring-hydroxylating dioxygenase from Sphingomonas CHY-1. Biochem. Biophys. Res. Commun. 2007, 352, 861-866. [CrossRef]

17. Wackett, L.P. Mechanism and applications of Rieske non-heme iron dioxygenases. Enzym. Microb. Technol. 2002, 31, 577-587. [CrossRef]

18. Boyd, D.R.; Sharma, N.D.; Brannigan, I.N.; McGivern, C.J.; Nockemann, P.; Stevenson, P.J.; McRoberts, C.; Hoering, P.; Allen, C.C.R. Cis-Dihydroxylation of Tricyclic Arenes and Heteroarenes Catalyzed by Toluene Dioxygenase: A Molecular Docking Study and Experimental Validation. Adv. Synth. Catal. 2019, 361, 2526-2537. [CrossRef]

19. Kauppi, B.; Lee, K.; Carredano, E.; Parales, R.E.; Gibson, D.T.; Eklund, H.; Ramaswamy, S. Structure of an aromatic-ringhydroxylating dioxygenasenaphthalene 1,2-dioxygenase. Structure 1998, 6, 571-586. [CrossRef]

20. Mahto, J.K.; Neetu, N.; Waghmode, B.; Kuatsjah, E.; Sharma, M.; Sircar, D.; Sharma, A.K.; Tomar, S.; Eltis, L.D.; Kumar, P. Molecular insights into substrate recognition and catalysis by phthalate dioxygenase from Comamonas testosteroni. J. Biol. Chem. 2021, 297, 101416. [CrossRef]

21. Ferraro, D.J.; Okerlund, A.L.; Mowers, J.C.; Ramaswamy, S. Structural basis for regioselectivity and stereoselectivity of product formation by naphthalene 1,2-dioxygenase. J. Bacteriol. 2006, 188, 6986-6994. [CrossRef]

22. Ferraro, D.J.; Gakhar, L.; Ramaswamy, S. Rieske business: Structure-function of Rieske non-heme oxygenases. Biochem. Biophys. Res. Commun. 2005, 338, 175-190. [CrossRef]

23. Vila, M.A.; Umpiérrez, D.; Seoane, G.; Rodríguez, S.; Carrera, I.; Veiga, N. Computational insights into the oxidation of mono- and 1,4 disubstituted arenes by the Toluene Dioxygenase enzymatic complex. J. Mol. Catal. B Enzym. 2016, 133, S410-S419. [CrossRef]

24. Jouanneau, Y.; Micoud, J.; Meyer, C. Purification and characterization of a three-component salicylate 1-hydroxylase from Sphingomonas sp. strain CHY-1. Appl. Environ. Microbiol. 2007, 73, 7515-7521. [CrossRef] [PubMed]

25. Schuler, L.; Jouanneau, Y.; Ní Chadhain, S.M.; Meyer, C.; Pouli, M.; Zylstra, G.J.; Hols, P.; Agathos, S.N. Characterization of a ring-hydroxylating dioxygenase from phenanthrene-degrading Sphingomonas sp. strain LH128 able to oxidize benz[a]anthracene. Appl. Microbiol. Biotechnol. 2009, 83, 465-475. [CrossRef] [PubMed]

26. Goris, J.; De Vos, P.; Caballero-Mellado, J.; Park, J.; Falsen, E.; Quensen, J.F.; Tiedje, J.M.; Vandamme, P. Classification of the biphenyl- and polychlorinated biphenyl-degrading strain LB400T and relatives as Burkholderia xenovorans sp. nov. Int. J. Syst. Evol. Microbiol. 2004, 54, 1677-1681. [CrossRef]

27. Auffret, M.; Labbé, D.; Thouand, G.; Greer, C.W.; Fayolle-Guichard, F. Degradation of a mixture of hydrocarbons, gasoline, and diesel oil additives by Rhodococcus aetherivorans and Rhodococcus wratislaviensis. Appl. Environ. Microbiol. 2009, 75, 7774-7782. [CrossRef] [PubMed]

28. Olowomofe, T.O.; Oluyege, J.O.; Aderiye, B.I.; Oluwole, O.A. Degradation of poly aromatic fractions of crude oil and detection of catabolic genes in hydrocarbon-degrading bacteria isolated from Agbabu bitumen sediments in Ondo State. AIMS Microbiol. 2019, 5, 308-323. [CrossRef]

29. Labute, P. Protonate3D: Assignment of ionization states and hydrogen coordinates to macromolecular structures. Proteins Struct. Funct. Bioinform. 2009, 75, 187-205. [CrossRef]

30. Madhavi Sastry, G.; Adzhigirey, M.; Day, T.; Annabhimoju, R.; Sherman, W. Protein and ligand preparation: Parameters, protocols, and influence on virtual screening enrichments. J. Comput. Aided. Mol. Des. 2013, 27, 221-234. [CrossRef]

31. Friesner, R.A.; Murphy, R.B.; Repasky, M.P.; Frye, L.L.; Greenwood, J.R.; Halgren, T.A.; Sanschagrin, P.C.; Mainz, D.T. Extra precision glide: Docking and scoring incorporating a model of hydrophobic enclosure for protein-ligand complexes. J. Med. Chem. 2006, 49, 6177-6196. [CrossRef]

32. Warren, G.L.; Andrews, C.W.; Capelli, A.M.; Clarke, B.; LaLonde, J.; Lambert, M.H.; Lindvall, M.; Nevins, N.; Semus, S.F.; Senger, S.; et al. A critical assessment of docking programs and scoring functions. J. Med. Chem. 2006, 49, 5912-5931. [CrossRef] 